\title{
From the athletes' perspective: A social-relational understanding of how coaches shape the disability sport experience
}

\author{
Veronica Allan, M. Blair Evans, Amy E. Latimer-Cheung \& Jean Côté
}

To cite this article: Veronica Allan, M. Blair Evans, Amy E. Latimer-Cheung \& Jean Côté (2019): From the athletes' perspective: A social-relational understanding of how coaches shape the disability sport experience, Journal of Applied Sport Psychology, DOI: 10.1080/10413200.2019.1587551

To link to this article: https://doi.org/10.1080/10413200.2019.1587551

Accepted author version posted online: 28 Mar 2019.

Submit your article to this journal $\widetilde{\pi}$

Џ Article views: 59

View Crossmark data \ulcorner 
From the athletes' perspective: A social-relational understanding of how coaches shape the disability sport experience

\author{
Veronica Allan ${ }^{1}$, M. Blair Evans ${ }^{2}$, Amy E. Latimer-Cheung ${ }^{3}$, and Jean Côté ${ }^{3}$ \\ ${ }^{1}$ School of Kinesiology and Health Science, York University, Toronto, Ontario, Canada \\ ${ }^{2}$ Department of Kinesiology and Physical Education, Pennsylvania State University, University \\ Park, Pennsylvania, United States of America \\ ${ }^{3}$ School of Kinesiology and Health Studies, Queen's University, Kingston, Ontario, Canada
}

\title{
Funding Acknowledgement:
}

This research was supported by the Coaching Association of Canada (Grant \#2015-001) and the Social Sciences and Humanities Research Council of Canada (SSHRC), including SSHRC Insight (Grant \#435-2014-0038), SSHRC Partnership (Grant \#895-2013-1021), and a SSHRC Joseph-Armand Bombardier Canada Graduate Scholarship (Award \#767-2015-1633).

\section{Corresponding Author:}

Correspondence concerning this article should be addressed to Veronica Allan, School of Kinesiology and Health Science, Faculty of Health, York University, Norman Bethune College, 
Room 341, 4700 Keele St., Toronto, Ontario, Canada, M3J 1P3. E-mail: vallan@ yorku.ca

From the athletes' perspective: A social-relational understanding of how coaches shape the disability sport experience

\begin{abstract}
The purpose of this study was to explore athletes' perceptions of how coaches shaped their experiences in disability sport throughout development. Athletes with physical disabilities $(N=21)$ participated in life history interviews. Participants outlined their sport history and responded to questions targeting the roles that coaches played in their development, which laid the foundation for broader conversations about how coaches shaped the disability sport experience. Using thematic analysis, patterns in coach knowledge, beliefs, and behaviours were captured in four themes. Three themes were discussed in relation to positive experiences in disability sport (consideration, collaboration, professionalism), while one theme was related to negative disability sport experiences (prejudice). The findings of this work are analyzed through the lens of the social-relational model of disability (Thomas, 1997, 2004, 2007), thus challenging the dominant discourse that underpins understandings of (dis)ability in the sport context. Practical recommendations for disability sport coaches include reflective practice and introspective examination of implicit biases and assumptions, as well as a focus on interpersonal skills that assist coaches in collaborating with athletes - thus encouraging the integration of sport- and disabilityspecific knowledge.

Keywords: coaching, disability, disability sport, qualitative, rehabilitation
\end{abstract}

Lay Summary: 
Athletes with physical disabilities were interviewed about how coaches shaped their experiences in sport over time. Differences in how coaches created positive experiences were identified at each stage of development, reflecting varied combinations of knowledge and behaviours. Negative experiences stemmed from perceptions of unfair treatment and inequality.

\section{From the athletes' perspective: A social-relational understanding of how coaches shape the disability}

\section{sport experience}

Coaches are widely recognized as one of the most important social agents in the sport environment (Horn, 2008). In able-bodied sport settings, decades of research document the significance of the coach-athlete relationship and its impact on athletes' experiences and outcomes (see Côté \& Gilbert, 2009; Horn, 2008 for reviews). As a result, many studies have investigated the behaviours, roles, and influences of expert, successful, experienced, elite, and great coaches (e.g., Becker, 2009; Debanne \& Fontayne, 2009). To consolidate this expansive body of work, Côté and Gilbert (2009) were the first to propose a comprehensive definition of coaching effectiveness, thus highlighting the dynamic interplay between coaches, their athletes, and the environment. They defined coaching effectiveness as "the consistent application of integrated professional, interpersonal, and intrapersonal knowledge to improve athletes' competence, confidence, connection, and character in specific coaching contexts" (Côté \& Gilbert, 2009, p. 316). However, coaching effectiveness has only recently been explored in sport for people with a disability (i.e., disability sport; Alexander, Bloom, \& Taylor, 2019).

Indeed, there are numerous ways of coaching to be successful or effective. Broadly speaking, the goal of the coach is to "help an athlete reach their full potential" (Short \& Short, 2005, p. S30) - but how "successful, "effective," and "potential" are defined will differ from person to person. Research examining disability sport coaches has primarily focused on how coaches learn and acquire knowledge in disability sport (Duarte, Culver, Trudel, \& Milistedt, 2018). In contrast, few studies have explicitly linked disability sport coaches' characteristics or behaviours to athletes' experiences and outcomes 
(Shirazipour et al., 2017; Turnnidge, Vierimaa, \& Côté, 2012). Perhaps most notably, the voices of athletes with disabilities - a central perspective in the disability sport context - are difficult to find within this literature (Alexander et al., 2019; Culver \& Werther, 2018). While there is preliminary evidence revealing how coaches play an important role in molding athletes' disability sport experiences (e.g., Shirazipour et al., 2017; Turnnidge et al., 2012), there is a need to better understand how coaches promote the development of athletes with disabilities (Martin \& Whelan, 2014). In particular, we need to understand the impact of disability sport coaches from the athlete's point of view.

To date, the body of literature focused on disability sport coaches is primarily descriptive and "coach-centric" (Townsend, Smith, \& Cushion, 2016). The learning experiences of coaches in disability sport have been explored extensively and in isolation from their athletes (e.g., Cregan, Bloom, \& Reid, 2007; Duarte \& Culver, 2014; McMaster, Culver, \& Werthner, 2012), despite the complex interactions and relational processes that shape the experiences of both coach and athlete. Several studies have shown that disability sport coaches are most likely to have experiential knowledge that stems from being or coaching an able-bodied athlete, as opposed to either general or sport-specific knowledge of disability (e.g., Cregan et al., 2007; Tawse, Bloom, Sabiston, \& Reid, 2012). While new coaches often lack experience with disability, opportunities to develop knowledge of disability and disability sport are minimal - both formally (e.g., certification programs) and non-formally (e.g., conferences; McMaster et al., 2012). Limited knowledge of and experience with disability may hinder coaches' ability to understand, reflect, and empathize with athletes. Among the few resources available for disability sport coach development, impairment-specific knowledge and skills are often emphasized (i.e., the focus is on coaching to improve sport performance against the limitations of impairment; Townsend et al., 2016). In other words, the medical model of disability — in which impairment is viewed as a personal tragedy and a problem to be solved (Smith \& Perrier, 2014; Thomas, 2004) - frequently underpins coach education and discourse in disability sport. 
Models of disability reflect particular ways of thinking about disability and the underlying assumptions that inform such understandings. As such, these models provide an important lens for understanding the experiences of persons with a disability. Disability scholars suggest that how coaches "understand disability and apply it to the coaching field will be influenced, either knowingly or unknowingly, by the models of disability that capture how disability is understood in society" (Townsend et al., 2016, p. 81). Nonetheless, few researchers in the area of disability sport coaching have applied models of disability within their work. In a recent study examining athletes with disabilities' perceptions of what makes a successful coach, Culver and Werthner (2018) took an important first step by acknowledging the social-relational model as an important perspective for disability sport coach development. The social-relational model of disability emphasizes the subjective experiences of individuals who live with impairment (Smith \& Perrier, 2014), and thus centralizes athletes' experiences in the disability sport context. Consequently, a social-relational understanding of how coaches shape the disability sport experience addresses important limitations in the coaching literature by (a) highlighting the connection between what coaches say or do and how athletes are affected (e.g., Shirazipour et al., 2017; Turnnidge et al., 2012), and (b) prioritizing athletes' voices in the process (e.g., Alexander et al., 2019; Culver \& Werther, 2018)

Couched within critical disability theory, the social-relational model of disability accounts for both internalized (e.g., feeling worthless or "lesser than") and externalized (e.g., inability to access a building) forms of oppression against persons with disabilities (Thomas, 1999). More specifically, the social-relational model recognizes disability as the result of social disadvantages or restrictions on participation, while acknowledging the biological or physiological aspect of impairment, as well as the psycho-emotional dimension of disability (Reeve, 2004). As such, the constructs that comprise the social-relational model include: (a) Impairment effects - the perceived physical (e.g., chronic pain) and social (e.g., need for social support) effects of reduced function; (b) constructions of disability - societal 
attitudes and discourse (e.g., stereotype that someone with a disability is weak or helpless); (c) structural barriers - being excluded from opportunities and services (e.g., a building that is only accessible via stairs); and (d) psychological well-being - the perceived effects of attitudinal and structural oppression on emotion and behaviour (e.g., lowered self-esteem as the result of internalizing a negative stereotype or feeling unable to participate; Thomas, 1999, 2004, 2007)

Using the social-relational model of disability as a lens for our research, the purpose of this study was to examine athletes with physical disabilities' perceptions of how coaches shaped their experiences in disability sport over the course of development. With the aim of providing information that may assist researchers and practitioners in promoting coaching practices that optimize athletes' experiences in disability sport, we wanted to hear about athletes' positive and negative experiences with disability sport coaches. In doing so, we sought to establish theoretical links between the perceived role that coaches played in athletes' sport experiences (for better or for worse) and the interaction of constructs that define disability according to the social-relational model (Thomas, 1999, 2004, 2007). Specifically, we aimed to understand how athletes with a disability perceived their coaches' knowledge, attitudes, and behaviours as they related to the quality of their sport experiences.

\section{Methodology and Methods}

The data for this study were collected concurrently with the data presented by Allan, Smith, Côté, Martin Ginis and Latimer-Cheung (2018). As such, the sampling procedures and participants included in these two studies are the same. Interviews were conducted together, before the coachfocused data were separated and discretely analyzed.

\section{Paradigm and Assumptions}

This study was grounded in interpretivism, which allows the researcher "to view the world through the perceptions and experiences of the participants" (Thanh \& Thanh, 2015, p. 24). From this perspective, the researcher draws on the views and experiences of participants to construct and 
interpret data in the context of the researcher's own background and experiences (Yanow \& SchwartzShea, 2011). As such, this research was underpinned by two assumptions: relativism (i.e., reality is multiple, subjective, and mind-dependent) and constructionism (i.e., knowledge is subjective and socially constructed). Adopting this perspective meant that we collaborated with participants to both interpret and co-construct patterns or themes within and between their individual views. Although we used themes to interpret participants' responses, this perspective also led us to focus on diversity across the sample by exploring how responses differed across developmental contexts. Alongside these assumptions, we used the social-relational model as a lens for understanding disability (see Townsend et al., 2016). More specifically, we explored how impairment entered the relationship between coach and athlete - as well as the broader sport context - by probing athletes' experiences of both bodily and socially-constructed realities.

\section{Participants and Sampling}

After obtaining ethics approval from the institution of the primary author, participants were recruited from disability sport clubs and organizations across Canada via e-mail. Participants were recruited using a combination of criterion-based purposive sampling and maximum variation sampling strategies (Sparkes \& Smith, 2014), ensuring that participants shared the characteristics that made them eligible for this study while also representing a diverse range of perspectives, respectively. Specifically, we sought the views of Canadian men and women, 18 years of age or older, with congenital or acquired physical disabilities and experience (i.e., a minimum of one season) participating in disability sport.

Disability sport was further operationalized to include competition and/or training for the purposes of competition as an individual or on a team at any competitive level, from recreational to elite. The final sample included 21 men and women with congenital and acquired physical disabilities. On average, participants were 33.7 years old $(S D=14.5)$ and reported 10.9 years of experience $(S D=8.9)$ participating in disability sport. Specific disability sport activities included adapted waterskiing, 
boccia, hand-cycling, para-alpine, para-archery, para-athletics, para-nordic, para-rowing, paraswimming, para-triathlon, power wheelchair hockey, sitting volleyball, sledge hockey, wheelchair basketball, wheelchair curling, and wheelchair rugby. Detailed demographic information is provided in Table 1.

\section{Data Collection}

The data for this project were collected during a two-part retrospective life history interview with each participant (see Adriansen, 2012). The interview protocol focused on the factors that shaped the quality of athletes' experiences in disability sport over time, including targeted questions to explore athletes' experiences and relationships with disability sport coaches. Correspondingly, athletes were asked about how coaches influenced their experiences in disability sport. Each life history interview consisted of two independent sessions, which were conducted in person $(n=7)$, over the phone $(n=4)$, or using an online interface (i.e., Skype; $n=10$ ) depending on the location of the participant. On average, 42 minutes of audio were recorded in the first session and 85 minutes of audio were recorded in the second session - a total of approximately 2 hours per participant. The duration of each interview was dictated by the participant, which corresponded to the amount of information included on the timeline.

In the first session, the interviewer and participant worked collaboratively to plot the participant's disability sport involvement (i.e., activities) as a timeline on a large sheet of banner paper, including related contextual information (e.g., location, competitive level, coaches) and major transitions or milestones (Adriansen, 2012). As a result, participants created a physical representation of their sport history, segmented into key points in time and activities that were described in detail. Each activity included on the timeline was followed-up with a specific probe designed to provide context for the research question proposed within the present study: "In a few words, how would you characterize the nature of your relationship with the coach?" The physical timelines were retained and used as a tool 
to facilitate recall and stimulate discussion during the second session (Adriansen, 2012). For online or phone interviews, the timeline was converted into an electronic format and e-mailed to the participant.

The purpose of the second session was to elicit more detailed information concerning participants' disability sport activities. After responding to more general questions, participants commented on how experiences with coaches related to the quality of their participation in disability sport. The coach-focused interview questions were organized according to the following categories: (a) activities: "How have coaches provided you with opportunities to get and/or stay involved in disability sport?", (b) relationships: "Who would you consider to be your most influential coach and why?", (c) environment: "How was the coach of this activity involved in shaping the disability sport environment?", and (d) outcomes: "Tell me about the most valued elements of your experience in disability sport. What role, if any, did the coach play in generating these feelings or outcomes?" To conclude, participants were asked to reflect back on their timeline and compare and contrast different coaches across their disability sport experiences.

The interview guide was adapted from the work of Shirazipour et al. (2017). Specifically, the questions were designed to relationally explore coaches' influences and roles across the levels of established social-ecological frameworks in developmental sport research (e.g., the Personal Assets Framework: Côté, Turnnidge, \& Evans, 2014). The co-constructed timeline provided both the researcher and the participant with opportunities to reflect on the participant's experiences before engaging in the second interview session. Throughout the second interview, follow-up questions and probes - tailored to each participant using the previously constructed timeline - supplemented the interview guide, providing opportunities for explanation and elaboration (Sparkes \& Smith, 2014).

\section{Data Analysis}

All interviews were audio recorded and transcribed verbatim. Each participant was provided with an opportunity to reflect on his or her interview transcript to extend and clarify our interpretations 
of the data (i.e., member reflections; Smith \& McGannon, 2017). Subsequently, we used the guidelines described by Braun, Clarke, and Weate (2016) to thematically analyze the data. Throughout data collection and analysis, the first author maintained a reflexive journal and approached the data with an understanding of the relational practices that shape disability.

To begin, Phases 1 and 2 involved a process of familiarization (i.e., reading and re-reading the edited interview transcripts while making informal notes) and line-by-line coding (i.e., systematically identifying and labelling ideas or concepts related to the research question), respectively. More specifically, the data was coded to reflect the characteristics and behaviours of participants' coaches, as well as how these characteristics and behaviours were linked to the athlete experience. During the third phase, coded extracts were organized into candidate themes by considering patterns in the perspectives of participants regarding the characteristics and behaviours of their coach. For example, how these characteristics and behaviours were linked to athletes' positive and negative experiences or the context. Until this point, the data had been inductively coded and organized. Moving forward with the analysis, the first author explored relationships between the inductively coded themes and the four constructs identified within the social-relational model of disability (i.e., impairment effects, constructions of disability, structural barriers, and psychological well-being), as well as interactions between themes and theoretical constructs. Phases 1-3 were completed independently by the first author, before engaging the second and fourth authors in Phases 4 and 5. Specifically, candidate themes were reviewed, discussed, and refined in Phase 4. During this phase, the second and fourth authors acted as critical friends to push the first author to consider inherent biases that may colour her interpretations and acted as a theoretical 'sounding board' for the findings (Sparkes \& Smith, 2014). As such, codes were iteratively revised and regrouped throughout this stage. The resulting themes were named in Phase 5, and the final phase involved writing up the report - led by the first author, and reviewed by all members of the research team. 


\section{Methodological Rigour}

Criteria for judging the quality of this qualitative research were not viewed as universal or preordained in nature. Aligned with ontological relativism and epistemological constructionism, a flexible list of criteria is provided as a framework for evaluation that is specific to the unique qualities of our research (Sparkes \& Smith, 2014; Smith \& McGannon, 2017). Drawing on the work of Kuzel and Engel (2001), we selected a list of criteria with the specific aim of ensuring that our work has both sound theoretical implications and meaningful pragmatic applications. Furthermore, we sought to address limitations of existing disability sport coaching research through our selection of criteria and the strategies used to ensure each one. These limitations include a lack of clear philosophical assumptions, disparate areas of focus, and the absence of athletes' perspectives (Townsend et al., 2016; Culver \& Werthner, 2018). These criteria, as well as the strategies used to achieve them, were embedded throughout the research process and are presented in Table 2.

\section{Results and Discussion}

Four themes corresponded to patterns in coaches' knowledge, beliefs, and behaviours that were linked to athletes' positive and negative experiences in disability sport. Three themes were considered important for optimizing athletes' disability sport experiences: professionalism, collaboration, and consideration. Participants stressed the interaction of knowledge and behaviours exemplified in each of these themes as vital for cultivating positive experiences in disability sport; however, several participants also highlighted the importance of certain elements depending on the context. Alternatively, a fourth theme reflected athletes' negative experiences with disability sport coaches: prejudice. When coaches engaged in discriminatory attitudes and practices, some participants were left feeling marginalized, uncomfortable, or unchallenged in their disability sport experiences. All four themes are contextually-situated and described in detail below, supported by extracts from a diverse range of participants. Woven into each theme is a discussion of relevant literature, including what these 
findings mean from a social-relational perspective of disability. To conclude, we synthesize the theoretical implications of these findings and provide practical recommendations for disability sport coaches.

\section{Professionalism}

The professionalism theme encompasses the competence or skill expected of a coach in relation to his or her specific disability sport, and is derived from relevant knowledge and experience. In the broader coaching literature, professional knowledge is defined as the specialized knowledge required to coach, which includes sport-specific, pedagogical, and procedural knowledge (Abraham, Collins, \& Martindale, 2006). Isabelle exemplified this theme when she described the effect of her first coach on her performance: "He was so knowledgeable. He really knew his job incredibly well, you know, my athleticism went from mediocre, like literally mediocre, to exceptional in one year." Professionalism was most often discussed in relation to the high-performance context, largely described as the international level of competition. "If it's at a high level, then the coach has to be very, very knowledgeable of the technical aspects, or if it's at a recreational level, then they got to have more knowledge maybe [of] a broader range of disabilities and adaptations," stated Frank, a retired national team athlete. Frank's view reflected a common perspective in high-performance disability sport - one in which impairment is "corrected" or "silenced" (Townsend et al., 2016). Correspondingly, coaches' professional knowledge is often focused on strategies or techniques that optimize sport performance despite the limitations perceived to accompany impairment.

Across contexts, however, participants valued two broad areas of expertise: sport-specific knowledge, including physical and psychological skills and strategies, and familiarity with the disability types of athletes in a particular sport. As such, the professional knowledge required of disability sport coaches may extend beyond traditional sport-specific knowledge to include knowledge of relevant disability types (e.g., Cregan et al., 2007), and the ability to apply that knowledge to sport skills and 
strategies. In fact, the ability to link these two areas of expertise was considered crucial in the disability sport setting. For example, Frank described his experience with an able-bodied sport coach who welcomed him into her training group: "She was very good at taking the principles and the basics of [disability sport] standing up and applying them to me sitting down." Disability-specific knowledge was also considered important to ensure that coaches "are comfortable with approaching the [athlete with a disability] and working with them," as Kris explained. From a social-relational perspective, the role of impairment needs to be both acknowledged and integrated into coaches' work in disability sport.

Athletes felt that coaches were more credible and relatable when they had built a foundation of sport- and disability-specific knowledge through their own experiences in sport (e.g., as an athlete or coach), especially if the coach also had personal experience with disability. In the words of Zach, who participated in wheelchair sports from an early age:

[My coach] was one of the best [disability sport] players in the world for 10 years, 10 to 15 years. She was a class one like me... so she knew my position, she knew what type of game I had to play. That was invaluable from a coaching perspective.

Several studies have discussed the potential for credibility and relatability derived from coaches and athletes with shared experiences of living with a disability (e.g., McMaster et al., 2012; Tawse et al., 2012). That being said, many participants felt that coaches' efforts to understand and empathize with athletes were paramount - regardless of whether or not the coach shared the disability experience. "I think it's one thing to have a coach in the sport, but it's another to have one who's been in it for a long time," discussed Roscoe, who went on to say: "[the coach] should understand disability and the lifestyle of disability."

An intrinsic understanding of disability was most often associated with a relational view that extended beyond the medical model discourse that frequently underpins coach education and athlete intervention in disability sport (Bush \& Silk, 2012; Townsend et al., 2016). In other words, coaches who 
shared the experience of disability and/or integrated what they knew about disability into their repertoire of professional knowledge were less likely to see impairment as a 'problem to be solved' or a 'challenge to be overcome' (e.g., DePauw, 2000) through 'top-down' coaching (e.g., Côté, 2006). Rather, participants stressed the importance of collaboration between coaches and athletes (as described in the next theme); the complexities of both disability and the social context were considered necessary aspects of coaching and performance.

Finally, participants discussed a range of behaviours and responsibilities necessary for translating the aforementioned sport- and disability-specific knowledge and experience into practice. Participants discussed the importance of detailed and organized practice plans, clear and consistent standards for behaviour, as well as contextually-appropriate activities and expectations. According to Patrick, coaches have a responsibility to provide "on-court guidance and direction," hold athletes "accountable to [their] training programs," and "ensure [they] are progressing in the right direction."

\section{Collaboration}

The second theme, collaboration, is defined as a reciprocal process of learning and development, characterized by mutually-shared beliefs, values, and expectations. "[The coach and the athlete] need to respect what each one brings to the table," stated Brittany. For example, Patrick recommended that coaches "don't try to be an expert on every disability, just learn from the individual with the disability - know their limits and work within them to get the most out of what they want." While the coach might be the expert in the sport, the athlete is an expert in their own disability; they can adapt and problem-solve together in order to optimize participation and performance. Participants described numerous communication strategies to enhance coach-athlete collaboration, including oneon-one time and varied means of communication (e.g., verbal instruction, use of a whiteboard, modelling skills) to ensure athletes' understanding.

Collaboration is a form of interpersonal knowledge, which involves the capacity for coaches to 
communicate with and relate to others in the sport environment, including athletes and their family members, as well as assistant coaches and other sport professionals (e.g., Bowes \& Jones, 2006). Perhaps most notably, the collaboration theme focused primarily on the interaction between coaches and athletes in disability sport. Consistent with existing disability sport research, collaboration highlighted the reciprocal nature of coach and athlete learning - both coaches and athletes contributed to the coaching process (Cregan et al., 2007; McMaster et al., 2012; Tawse et al., 2012). Interpersonal skills, while important in any coaching context, may be particularly salient in disability sport due to the challenges and intricacies of navigating varied disability types in a world that caters largely to the ablebodied person (e.g., Falcão, Bloom, \& Loughead,, 2015; Tawse et al., 2012). As such, the value placed upon collaboration is particularly notable given that it aligns closely with a social-relational lens: coaches and athletes co-construct knowledge through an "unequal, dynamic process" that has implications for the quality of athletes' experiences in disability sport (Townsend et al., 2016).

Collaboration was the most ubiquitous theme, described as an important quality from the time an athlete enters competitive sport and remaining a desirable aspect of coaching over the course of an athlete's development. "I think initially the most important thing is that it is fun. No matter what the level of the athlete, you need to first create a love for the sport," stated Brittany. "I think from that point on...the program needs to match the goal of the athlete." Brittany highlighted the importance of creating positive early sport experiences and tailoring approaches to training as the athlete develops. Morley provided a more nuanced perspective, describing accountability on either end of the coach-athlete partnership:

I think that there's responsibility on the coaches to sort of set that bar so that that athletes understand where that level of commitment is, but I think there's also responsibility in the athletes to make sure that they're putting their best foot forward and trying to constantly improve but again, like I said, it's a learning process. 
While collaboration was particularly important when it came to addressing disability in the sport context, it was also an important means of nurturing development in line with athletes' goals and desires, thus accounting for the subjective experience and personal agency of athletes within the broader structure of disability sport coaching (Smith \& Perrier, 2014).

To build the foundation for a collaborative learning environment, coaches developed and maintained personal relationships with athletes. Isabelle stated, "I think that it is really important that the coach knows the person, like takes the time to get to know them and takes a personal interest in them." In doing so, coaches demonstrated care and concern for athletes' well-being. Consequently, athletes tended to feel more secure and comfortable with their coach, and coaches felt more relaxed "getting up close and personal," as Nina explained, when addressing athletes' needs. The importance of building personal relationships with athletes, underpinned by a genuine belief in the athletes' potential, is also underscored in Turnnidge and colleagues' (2012) study of a model sport program for youth with disabilities - among a plethora of similar findings in able-bodied sport settings (see Turnnidge \& Côté, 2018 for a review). According to Brittany, "the best [coaches] are those that validate and uplift their athletes, and aim to make them competent and independent." Coaches demonstrated that they believed in their athletes by dedicating time and effort to their development, recognizing accomplishments, and providing tailored feedback, encouragement, and reassurance. As Graham explained:

Some of the players in the house league are players that physically can't do much and so um they don't do much and when they do something like deflect a ball, whether it's on purpose or the ball happens to hit them, [the coach] will go out of their way to congratulate the player and make the player feel like they're making a difference to their team... and that is really not only a positive thing for the players themselves but I think a positive thing for the whole team because that way the whole team can see value in everything every player is doing. 
Several participants also discussed how their coaches created a culture for collaboration that extended beyond individual coach-athletes relationships to the broader dynamic of the team. Falcão and colleagues (2015) identified a number of strategies used by Paralympic coaches to foster cohesion among their athletes, including the use of communication to set goals and build positive coach-athlete relationships. In a similar vein, participants in this study described how coaches facilitated opportunities for team bonding (e.g., organizing social events) and eased access and removed barriers to participation (e.g., calling ahead to hotels or venues to ensure they are accessible). Team culture was a crucial aspect of participation for athletes such as Anna, who explained that “if someone on the team can't do something, all we have to do is tell [coach] and she'll figure out a way for that person to do it."

\section{Consideration}

Building a foundation for both collaboration and professionalism, consideration encompasses a reflective process through which coaches may recognize and situate their own biases and assumptions (e.g., Taylor, Werthner, Culver, \& Callary, 2015). Consideration refers to the coach's ability to anticipate, understand, and reflect on athletes' needs and goals, as well as the effects that one's beliefs and actions will have on athletes' outcomes, which encompasses personal views of both sport and disability.

"Understanding would be my word, so, that openness and understanding and kind of, a coach that understands where I'm coming from in terms of my own personal space, but also as an athlete," explained Nina, summing up the consideration theme. Consideration aligns with Côté and Gilbert's (2009) conception of coaches' intrapersonal knowledge, encompassing self-understanding, introspection, and reflection. According to Gilbert and Trudel (2001), coach reflection is necessary to translate experience into relevant knowledge and skills. As such, consideration represents a key aspect of how coaches understand disability in the sport context, and apply that understanding to their coaching practice.

In general, participants believed that coaches' perceptions of disability and disability sport 
strongly influenced their approach to training and degree of comfort when working with athletes. According to Nina, coaches need to "open their eyes to the fact that disability isn't kind of how it's stereotyped." Athletes expressed a desire to be treated equally to their able-bodied peers and have disability sport taken seriously in the broader sport domain. "I think I get along well with my coach because he really understands disability, and he doesn't put my disability as an excuse for anything," reflected Roscoe. Although disability is an integral part of the athlete and should be addressed when needed, the focus should remain on the person and their goals or reasons for participating. In the words of Joanne, coaches should "focus on what [athletes with disabilities] can do, not what they can't do." As shown, the consideration theme draws attention to the importance of understanding and addressing disability while maintaining a focus on aspects of the athlete that exist separate from their disability (e.g., their goals or aspirations). This finding shows how differential understandings of disability, from the medical model (i.e., disability is silenced) to the social model (i.e., disability is integral), may inform a broader social-relational understanding of disability (see Townsend et al., 2016). Reinforcing this point, several participants discussed the oppressive effects of coaches who aligned their beliefs with negative stereotypes of disability (e.g., incompetence) or performance-oriented discourse that places a premium on more abled athletes (as shown below in the prejudice theme). As such, the consideration theme draws attention to the coach's ability to influence athletes' psychological wellbeing - a key component of the social-relational model (e.g., Haslett, Fitzpatrick, \& Breslin, 2017). In a similar vein, the words or actions of coaches were thought to have a profound effect on an athlete's confidence. As such, participants described the best coaches as those who were both deliberate and aware of their influence as coaches. In the words of Brittany: "I firmly believe, regardless of your level of coaching...[that] you as a leader, have an ability - a unique ability - to have an impact on your athletes' life both on the court and off it as well." Coaches who are deliberate and thoughtful are likely to make positive connections with athletes that support their overall development. Expanding on a 
previous quote, Roscoe went on to say, "[My coach] totally gets me as a person, like he understands that I'm not just about sport, like kind of school comes first, I want to get a job...he gets that aspect, and incorporates it into my plans." The ability to recognize how sport fits into the broader context of athletes' lives, and recognize the potential impact that one has as a coach, demonstrates a respect for athletes that encouraged meaningful participation and allowed athletes to develop in diverse areas of their lives. "She kind of respects that I have a life beyond sport," stated Frank, describing the response of his coach to his retirement from high performance disability sport. "That sort of respect is really great."

One way that coaches can learn about athletes' needs and abilities is through efforts to understand and empathize. "Maybe get an understanding of how the athlete has to live their life... maybe that helps out in the long-term [on] the sports side," speculated Danielle. Joanne recommended that new coaches should try the sport first, as demonstrated in the following exchange with the interviewer:

Joanne: You can only learn so much from books and whatever like seminars and things like that, but if you really get in there... and try the equipment and know how the equipment works, then you can teach it and coach it to your athletes...

Interviewer: So actually, trying the adaptive version of the sport and having that experience? Joanne: Yeah because they know what the athlete's going through, how the athlete feels while they're in the sit ski or on the water sit skiing or cross-country skiing, whatever!

Coaches who live with a disability or have previous experience in disability sport may find empathizing with their athletes easier than able-bodied coaches (Cregan et al., 2007; McMaster et al., 2012; Tawse et al., 2012). As Zach claimed, "[My coach] is probably the most important person in my life outside of my parents, because she was the first person I've really met with a disability who'd gotten to where I wanted to be." Nonetheless, coaches without relevant experience can deepen their understanding by 
trying out the sport and equipment for themselves.

We must also note that the consideration theme involved more than simply reflecting on one's practice and experience: it includes an introspective examination of one's biases and assumptions related to disability and sport. Taylor and colleagues (2015) examined reflective practice among four disability sport coaches, highlighting the need to reflect with a "lens of adaptability" - described by one able-bodied coach as a continuous process of self-questioning. The importance of "reflecting with others" - for example, reflecting out loud with an athlete - was another important finding (Taylor et al., 2015), lending support to the notion that coaches can promote positive athlete experiences through strategies related to collaboration (e.g., listening to athletes) used in tandem with consideration (e.g., reflection).

Finally, when participants knew that their coach understood their disability and their goals, and treated them as equals alongside other athletes, they were more likely to continue working with that coach. As Roscoe explained, "It was just nice to have someone who is really interested in my level, my classification level, and that's kind of why I stuck with him." Thus, consideration may play an important role in motivating sustained interest and participation. Additionally, based on the experiences of some participants in this study, the coach could play an important role in initiating first contact between potential athletes and disability sport. For example, Kris was approached by the coach of a local sledge hockey team while waiting to pick up a prescription at the pharmacy. According to Henry, a coach who reaches out to athletes, "helps the athletes to be motivated or to feel...accountable."

\section{Prejudice}

Due to either a lack of knowledge and experience or generalized stereotypes of disability and disability sport, the prejudice theme encompasses oppressive attitudes or behaviours. According to Thomas (2007), disablism is a form of oppression that involves socially imposed restrictions (i.e., structure) and the undermining of psycho-emotional well-being (i.e., agency). Correspondingly, the 
social-relational model accounts for both structure and agency in its conceptualization of disability (Thomas, 2007). Drawing on the social-relational model, the prejudice theme offers clear examples of how both attitudinal and structural barriers (emanating from the coach and/or their behaviours) interact to negatively impact athletes' psycho-emotional well-being in disability sport.

To begin, some participants described experiences in which coaches did not treat athletes with disabilities as equal to able-bodied athletes. These coaches lowered their expectations of disability sport athletes and demonstrated a clear lack of effort and engagement in their athletes' training. For example, Quinn believed that one of her coaches (on a national team) did not want to be a disability sport coach, and was only using his position as a "stepping stone" to reach a more prominent position in able-bodied sport:

I believe he didn't like his job, just because he never coached; he was not present at most of our races or training camps. So, we were on our own for a whole year. We didn't have the budget, we had to fundraise our way through training camps, and we had to find our own coach, so it was really hard.

In terms of structural barriers, Quinn and her teammates faced a lack of financial support that influenced access to equipment and competitive opportunities. They did not have the informational guidance or support of a regular coach, and access to other support services (e.g., physical therapy) were limited. Quinn felt that her coach behaved in such a way because he did not view disability sport as "real" sport, reflecting the stereotype that individuals with disabilities are weak or incompetent (and therefore incapable of performing athletic feats; Silva \& Howe, 2012). Such a stereotype represents an attitudinal barrier to participation (e.g., Haslett et al., 2017).

In a similar vein, some participants discussed situations in which coaches favoured athletes who were "more abled" than others. More specifically, athletes with higher levels or function (with or without a disability) were prioritized over athletes with lower levels of function. As Morley described: 
He had in his mind what he was looking for um in an athlete in terms of physical features or what he calls 'ideal disabilities', things like that... he didn't really pay attention to me until I was, you know, showing that I could produce speed and showing that I was fast.

Roscoe, an athlete with quadriplegia, described feeling "brushed to the side" when he trained alongside the paraplegic athletes in his training group. The psycho-emotional dimension of disability becomes clear in the language of Morley and Roscoe: they are describing experiences of neglect in which they did not feel worth the time or attention of their respective coaches.

In direct contrast to the consideration theme, coaches who lacked empathy or understanding were more likely to show discomfort around athletes with disabilities, over-sympathize, and struggle to appropriately adapt skills or activities in a way that would include all athletes - thus negatively influencing coaches' capacity for professionalism and collaboration. As Tom explained, "They sometimes treated you as if, being in a wheelchair, they felt sorry for you...and some of them still exhibit that as if to say, 'poor [Tom] is in a wheelchair.'" On the other hand, Quinn experienced a lack of sensitivity from her coach when returning to her sport post-injury: “'Are you going to be scared today?' It was always very negative comments, and I didn't want to go to the [facility] anymore." A lack of empathy and understanding was often attributed to a lack of knowledge and education. According to Nina:

We got new coaches almost every year, and every year it was teaching them the same thing, and it got really frustrating, just like, I don't want to start from scratch again, and I don't want to have to tell them what a disability is, I feel like they should know this coming in, especially when we were at the level that we were at.

Nina's frustrations were echoed by Kris, a wheelchair athlete who worked with a coach intent on 'forcing' able-bodied technique (requiring core muscles that he could not use): "I had a coach that was just, hammered on me, hammered on me that I had to sit up straight...to the detriment of my [performance]." 
Each of these examples of prejudice are informed by medicalized discourse in which disability is viewed as a personal tragedy and a problem to be solved (Smith \& Perrier, 2014). When viewed through a social-relational lens, prejudicial actions have the potential to negatively impact athletes' emotions and behaviours in a way that is unlikely to optimize performance or motivate sustained interest and participation (e.g., Haslett et al., 2017; Townsend et al., 2016). Only one other study has explored negative coaching behaviours from the perspectives of disability sport athletes, and revealed similar findings: Athletes felt inferior and lacked trust in coaches who were manipulative or selfish, and felt dissatisfied with themselves and their coaches when the coach did not treat individuals with disabilities equally or respectfully (Alexander, 2017). While most participants described positive experiences with their coaches, these examples draw attention to the oppression experienced by athletes in disability sport.

\section{A Social-Relational Understanding of Disability Sport Coaching}

In summary, the interaction of coaches' knowledge and behaviours as presented in the consideration, collaboration, and professionalism themes promotes a social-relational understanding of disability sport coaching that has the potential to create positive experiences for athletes with a disability. More specifically, coaches' ability to self-reflect and introspectively examine their own biases and assumptions (i.e., consideration) played an important role in their capacity to anticipate athletes' needs and centralize athletes' experiences (i.e., collaboration), as well as integrate sport- and disability-specific knowledge (i.e., professionalism). Opportunities for collaboration, encompassing the co-construction of knowledge between coaches and athletes with mutually-shared goals and beliefs, may further facilitate professionalism, while encouraging consideration through shared reflection and efforts to understand or empathize with athletes. On the other hand, negative effects on athletes' psycho-emotional well-being were exemplified in 
the prejudice theme - demonstrating how coaches might perpetuate attitudinal and structural barriers to the athletes' participation in disability sport. Prejudice was often associated with a lack of consideration, collaboration, and/or professionalism.

When considering the four constructs that underpin the social-relational model of disability (i.e., impairment effects, constructions of disability, structural barriers, and psychoemotional well-being; Thomas, 1997, 2004, 2007), we can further break down the interplay that occurs between each of these themes to enhance our understanding of how coaches shape athletes' experiences in disability sport. While the physical effects of impairment were rarely discussed in relation to disability sport coaching, the social effects were emphasized. Needs for assistance or support were discussed within the professionalism theme, highlighting athletes' desire for coaches to have disability-specific knowledge that could be integrated with sportspecific knowledge (e.g., to appropriately adapt skills or activities). Making efforts to empathize with athletes was discussed as an example of how coaches might improve disability-specific knowledge, thus drawing attention to the importance of consideration as a tool for understanding the perceived physical and social effects of an athlete's impairment.

Findings related to constructions of disability (i.e., societal attitudes and discourse) and structural barriers (i.e., access and opportunity) reflect a similar pattern when considering athletes' discussions of the social and physical effects of impairment. More specifically, the social aspect - coaches' beliefs and attitudes — formed the core of each theme, while structural barriers - the physical aspect — were viewed as a downstream effect of how coaches viewed disability and disability sport. Constructions of (dis)ability in sport are often associated with the medical model (Silva \& Howe, 2012), such that athleticism defines ability and the coach's role revolves around correcting or eliminating the perceived limitations of impairment (Townsend et 
al., 2016). In terms of structural barriers, the discourse or beliefs that shaped coaches' understanding of disability appeared to influence the role they played in facilitating access or removing barriers to athletes' participation in disability sport (e.g., advocating for equal funding, facilitating access to equipment, calling ahead to ensure the training facility is accessible). According to the participants in this study, coaches who subscribed to the medical model included (a) those who did not take disability sport seriously (i.e., did not provide enough support, thus limiting access and opportunity) and (b) those who over-sympathized with athletes (i.e., provided too much support, thus limiting personal agency).

Finally, according to Haslett and colleagues (2017), "repeated exposure to negative interactions with the social and built environment can result in people placing limits on what they can do and what they can become" (p. 63) - such as avoiding participation in sport. This encompasses the oppressive effects of attitudinal and structural barriers on psycho-emotional well-being (Thomas, 2004), as exemplified in the prejudice theme. Athletes described feeling frustrated with coaches' lack of knowledge or understanding, neglected when coaches were absent or failed to provide them with adequate attention, and "lesser than" in relation to coaches' perceived favouring of "more abled" athletes. One participant (Quinn) was even compelled to stop going to practice, and eventually quit the sport altogether. Alternatively, participants provided examples of how coaches positively influenced their psycho-emotional well-being in the collaboration theme. Athletes felt more confident when coaches demonstrated a genuine belief in their potential and worked collaboratively with the athlete to achieve their goals (Turnnidge et al., 2012).

\section{Practical Implications for Disability Sport Coaches}

Moving towards a social-relational understanding of disability, coaches must first look inward to examine the biases and assumptions they hold about disability and disability sport (e.g., Taylor et al., 
2015). For example, coaches might question their able-bodied assumptions (e.g., "How did I learn as an able-bodied athlete, and will that mode of learning work for this athlete?") and acknowledge when they don't know the best approach for a particular athlete. In doing so, they might challenge the medical model as the dominant discourse in disability sport coaching and work towards centralizing athletes' experiences in the coaching process (Townsend et al., 2016). When coaches are unfamiliar with disability or a specific disability sport, efforts to understand and empathize with athletes are critical. For example, coaches may wish to test the equipment and try out the disability sport for themselves, or talk to athletes about their daily routines and how they affect sport participation and performance (e.g., Tawse et al., 2012). Correspondingly, the process of co-constructing knowledge with athletes may assist coaches in integrating sport- and disability-specific knowledge that optimizes the athlete experience (e.g., Cregan et al. 2007; McMaster et al., 2012; Tawse et al., 2012).

With this in mind, behaviours demonstrated in the consideration (e.g., efforts to understand and empathize) and collaboration (e.g., asking athletes what works best for them) themes may assist coaches in anticipating and addressing athletes' needs in and beyond the sport environment - thus reducing structural barriers to participation in disability sport. For example, when planning a team social event, the coach would know to locate an accessible venue (e.g., restaurant) and call ahead with specific instructions (e.g., removing chairs at a table where individuals in wheelchairs will be seated). Professional knowledge and behaviours (e.g., knowledge of adaptations required for a particular activity or skill) are also important for ensuring access and opportunities to participate (Shirazipour et al., 2017). When translating new skills or strategies into coaching, the use of a detailed practice plan - specifying the timing and equipment required for each activity, as well as the range of available modifications may be useful, particularly for new disability sport coaches. Coaches may also wish to draw on their connections with other coaches and athletes when learning to apply traditional sport knowledge to the unique needs of disability sport athletes. In doing so, the repertoire of strategies available to a coach is 
substantially increased (Duarte \& Culver, 2014; McMaster et al., 2012).

While several of the skills and strategies highlighted thus far apply to coaching in any context, disability should be recognized as an integral component of the disability sport athlete and situated according to the needs and preferences of each person. Although disability is an integral part of the athlete and should be addressed when needed, the focus should remain on the person and their goals or reasons for participating. A holistic understanding of the athlete provides important context regarding his or her motivation(s) for participating in disability sport (Townsend et al., 2016). Coaches have the potential to positively contribute to athletes' psycho-emotional well-being by demonstrating genuine interest in and care or concern for athletes (e.g., asking questions about athletes' lives outside of sport; Turnnidge et al., 2012) and treating athletes with fairness and respect (Haslett et al., 2017).

\section{Conclusion}

By explicitly adopting a social-relational lens to examine how coaches shaped the experiences of athletes in disability sport, this paper addresses a substantive gap in the coaching literature. Specifically, the voices of athletes with disabilities were highlighted as an integral and under-represented perspective in disability sport coaching research. As such, this paper took an important step towards engaging coaching research with the field of disability studies (Culver \& Werther, 2018; Townsend et al., 2016). For the benefit of researchers and practitioners alike, the constructs that underpin the socialrelational model are clearly defined and used to provide practical examples of how coaches might challenge the dominant - and potentially harmful - medicalized discourse that pervades disability sport. The findings of this paper offer a valuable framework for research and practice, and an essential perspective on disability sport coaching.

\section{References}

Abraham, A., Collins, D., \& Martindale, R. (2006). The coaching schematic: Validation through expert coach consensus. Journal of Sports Sciences, 24(6), 549-564. 
Adriansen, H. K. (2012). Timeline interviews: A tool for conducting life history research. Qualitative Studies, 3, 40-55.

Alexander, D., Bloom, G. A., \& Taylor, S. L. (2019). Female Paralympic athlete views of effective and ineffective coaching practices. Journal of Applied Sport Psychology. Advance online publication. DOI: 10.1080/10413200.2018.1543735

Allan, V., Smith, B., Côté, J., Martin Ginis, K. A., \& Latimer-Cheung, A.E. (2018).Narratives of participation among individuals with physical disabilities: A life-course analysis of athletes' experiences and development in disability sport. Psychology of Sport and Exercise, 37, 170178.

Becker, A. (2009). It's not what they do, it's how they do it: Athlete experiences of great coaching. International Journal of Sports Science and Coaching, 4, 93-119.

Bowes, I. \& Jones, R. (2006). Working at the edge of chaos: Understanding coaching as a complex interpersonal system. The Sport Psychologist, 20, 235-245.

Braun, V., Clarke, V., \& Weate, P. (2016). Using thematic analysis in sport and exercise research. In B. Smith \& A. C. Sparkes (Eds.), Routledge Handbook of Qualitative Research in Sport and Exercise (pp. 191-205). New York, NY: Routledge.

Bush, A. J., \& Silk, M. L. (2012). Politics, power \& the podium: Coaching for Paralympic performance. Reflective Practice: International and Multidisciplinary Perspectives, 13, 471-482.

Côté, J. (2006). The development of coaching knowledge. International Journal of Sports Science \& Coaching, 1, 217-222

Côté, J., \& Gilbert, W. (2009). An integrative definition of coaching effectiveness and expertise. International Journal of Sports Science \& Coaching, 4, 307-323.

Côté, J., Turnnidge, J., \& Evans, M. B. (2014). The dynamic process of development through sport. 
Kinesiologia Slovenica, 20, 14-26.

Cregan, K., Bloom, G. A., \& Reid, G. (2007). Career evolution and knowledge of elite coaches of swimmers with a physical disability. Research Quarterly for Exercise and Sport, 78, 339-350.

Culver, D. M., \& Werthner, P. (2018). Voices: para athletes speak. Qualitative Research in Sport, Exercise and Health, 10, 167-175.

Debanne, T. \& Fontayne, P. A. (2009). A study of successful experienced elite handball coach's cognitive processes in competition situations. International Journal of Sports Science and Coaching, 4, 1-16.

DePauw, K. P. (2000). Social-cultural context of disability: Implications for scientific inquiry $\quad$ and professional preparation. Quest, 52, 358-368

Duarte, T., \& Culver, D. (2014). Becoming a coach in developmental adaptive sailing: a lifelong learning perspective. Journal of Applied Sport Psychology, 26, 441-456.

Duarte, T., Culver, D., Trudel, P., \& Milistedt, M. (2018). Parasport coach development: Evidence from the Canadian context. LASE Journal of Sport Science, 9, 78-90.

Falcão, W. R., Bloom, G. A., \& Loughead, T. M. (2015). Coaches' perceptions of team cohesion in Paralympic sports. Adapted Physical Activity Quarterly, 32, 206-222.

Gilbert, W., \& Trudel, P. (2001). Learning to coach through experience: Reflection in model youth sport coaches. Journal of Teaching in Physical Education, 21(1), 16-34.

Haslett, D., Fitzpatrick, B., \& Breslin, G. (2017). The psychological influences on participation in wheelchair rugby: A social relational model of disability. Acta Universitatis Carolinae: Kinanthropologica, 53(1), 60-78.

Horn, T. S. (2008). Coaching effectiveness in the sport domain. In T. S. Horn (Ed.), Advances in Sport Psychology (3 ${ }^{\text {rd }}$ ed., pp. 239-267). Champaign, IL: Human Kinetics.

Kuzel, A. J., \& Engel, J. D. (2001). Some pragmatic thoughts about evaluating qualitative health 
research. In J. M. Morse, J. M. Swanson, \& A. J. Kuzel (Eds.), The Nature of Qualitative Evidence (pp. 115-140). Thousand Oaks, CA: Sage.

Martin, J. J., \& Whalen, L. (2014). Effective practices of coaching disability sport. European

Journal of Adapted Physical Activity, 7, 13-23.

McMaster, S., Culver, D., \& Werthner, P. (2012). Coaches of athletes with a physical disability: a look at their learning experiences. Qualitative Research in Sport, Exercise and Health, 4, 226-243.

Reeve, D. (2004). Psycho-emotional dimensions of disability and the social model. In C. Barnes \& G. Mercer (Eds.), Implementing the social model of disability: Theory and research (pp. 83-100). Leeds: The Disability Press.

Shirazipour, C. H., Evans, M. B., Caddick, N., Smith, B., Aiken, A. B., Martin Ginis, K. A., \& LatimerCheung, A. E. (2017). Quality participation experiences in the physical activity domain: Perspectives of veterans with a physical disability. Psychology of Sport and Exercise, 29, 40-50.

Short, S. E., \& Short, M. W. (2005). Role of the coach in the coach-athlete relationship. Lancet, 366, S29-S30.

Silva, C. F., \& Howe, P. D. (2012). Difference, adapted physical activity and human development: Potential contribution of capabilities approach. Adapted Physical Activity Quarterly, 29, 25-43.

Smith, B. M., \& Perrier, M. J. (2014). Disability, sport, and impaired bodies: A critical approach. In R. Schinke \& K. R. McGannon (Eds.), The psychology of sub-culture in sport and physical activity: A critical approach (pp. 95-106). London, UK: Psychology Press.

Smith, B. \& McGannon, K. R. (2017). Developing rigor in qualitative research: Problems and opportunities within sport and exercise psychology. International Review of Sport and Exercise Psychology. Advance online publication.

Sparkes, A. C., \& Smith, B. (2014). Qualitative research methods in sport, exercise, and health: From process to product. London, UK: Routledge. 
Tawse, H., Bloom, G. A., Sabiston, C. M., \& Reid, G. (2012). The role of coaches of wheelchair rugby in the development of athletes with a spinal cord injury. Qualitative Research in Sport, Exercise and Health, 4, 206-225.

Taylor, S., Werthner, P., Culver, D., \& Callary, B. (2015). The importance of reflection for coaches in disability sport. Reflective Practice, 16, 269-284.

Thanh, N. C., \& Thanh, T. T. L. (2015). The interconnection between interpretivist paradigm and qualitative methods in education. American Journal of Educational $\quad$ Science, 1(2), 24-27.

Thomas, C. (1999). Female forms: Experiencing and understanding disability. London: McGraw-Hill Education (UK).

Thomas, C. (2004). Rescuing a social relational understanding of disability. Scandinavian Journal of Disability Research, 6(1), 22-36.

Thomas, C. (2007). Sociologies of disability, 'impairment', and chronic illness: Ideas in disability studies and medical sociology. London: Palgrave.

Townsend, R. C., Smith, B., \& Cushion, C. J. (2016). Disability sports coaching: Towards a critical understanding. Sports Coaching Review, 4, 80-98.

Tracy, S. J. (2010). Qualitative quality: Eight "big-tent" criteria for excellent qualitative research.

Qualitative Inquiry, 16, 837-851.

Turnnidge, J., \& Côté, J. (2018). Applying transformational leadership theory to coaching research in youth sport: A systematic literature review. International Journal of Sport and Exercise Psychology, 16(3), 327-342.

Turnnidge, J., Vierimaa, M., \& Côté, J. (2012). An in-depth investigation of a model sport program for athletes with a physical disability. Psychology, 3, 1131-1141.

Yanow, D., \& Schwartz-Shea, P. (2011). Interpretive approaches to research design: Concepts and processes. Netherlands: Routledge. 
Table 1 Participant demographic information

\begin{tabular}{|c|c|c|c|c|c|}
\hline Pseudonym & Gender & Age & Impairment & $\begin{array}{c}\text { Years in } \\
\text { Parasport }\end{array}$ & $\begin{array}{c}\text { Highest } \\
\text { Competitive Level }\end{array}$ \\
\hline Anna & Female & 21 & Cerebral Palsy & 4 & National \\
\hline Brittany & Female & 30 & Lower Limb Amputation & 15 & International \\
\hline Carly & Female & 42 & Quadriplegia & 14 & International \\
\hline Danielle & Female & 23 & Spina Bifida & 2 & National \\
\hline Evan & Male & 32 & Cerebral Palsy & 19 & International \\
\hline Frank & Male & 48 & Paraplegia & & International \\
\hline Graham & Male & 27 & Muscular Dystrophy & & International \\
\hline Henry & Male & 30 & Paraplegia & 9 & Regional \\
\hline Isabelle & Female & 49 & Upper Limb Amput & 4 & International \\
\hline Joanne & Female & 38 & Paraplegia & 17 & International \\
\hline Kris & Male & 64 & Paraplegia & 36 & International \\
\hline Leo & Male & 24 & Increased Muscle Tone & 15 & National \\
\hline Morley & Male & 26 & $\begin{array}{l}\text { wer Limb Reduced } \\
\text { Strength }\end{array}$ & 2 & International \\
\hline Nina & Female & & Paraplegia & 7 & International \\
\hline Owen & Male & & Paraplegia & 4 & Regional \\
\hline Patrick & Male & & Quadriplegia & 4 & National \\
\hline Quinn & Female & 19 & Upper Limb Amputation & 2 & International \\
\hline Roscoe & Male & 21 & Quadriplegia & 4 & National \\
\hline Sylvie & Female & 19 & Paraplegia & 7 & National \\
\hline Tom & Male & 73 & Paraplegia & 9 & Regional \\
\hline Zach & Male & 26 & Cerebral Palsy & 20 & National \\
\hline
\end{tabular}


Table 2 A flexible list of criteria for evaluating the methodological rigour of this study

\section{Criteria}

Sound Assumptions: Are the

philosophical assumptions of the

research stated and consistent with the research processes and/or product?
Quality Connections: Do the researchers demonstrate sensitivity to the linkage between assumptions, facts, values, interpretations, and theories?

\section{Strategies Used to Achieve Criteria}

Grounded in interpretivism, philosophical assumptions are clearly articulated and present throughout data collection (e.g., co-construction of timelines) and analysis (e.g., critical friends as "theoretical sounding board") (Kuzel \& Engel, 2001).

The first author maintained reflexive journal, and the second and fourth authors acted as critical friends - thus offering careful and critical opportunities for connection, particularly within the analysis (Sparkes \& Smith, 2014). For example, when the findings were linked to coaching effectiveness.

An audit trial was maintained for all methodological decisions, and the first author kept a reflexive journal in which factors influencing methodological decisions were discussed (Tracy, 2010).
Plausibility: Are the findings plausible and consistent with existing theory?
Rich Rigour: Do the researchers sufficiently justify methodological decisions and demonstrate an understanding of what the chosen methods will produce?

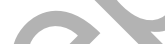

Collaboration: Does the inquiry involve a community of inquirers, and do the researchers account for the impact of social structures/processes?
The voices of athletes with disabilities are represented and considered in the broader context of parasport coaching, consistent with the social relational model of disability that underpins this research (Townsend et al., 2016). Participants were provided with an opportunity reflect on the transcript from their interview (Smith \& McGannon, 2017). 